\title{
Del colonialismo \\ a la emancipación epistémica. \\ Un aporte doble al debate \\ sobre la relación entre imperialismo y derecho internacional
}

Reseña de: Anghie, Antony; Koskenniemi, Martti y Orford, Anne. Imperialismo y derecho internacional: historia y legado, Estudio preliminar de Eslava, Luis; Obregón, Liliana y Urueña, René. Bogotá: Siglo del Hombre Editores, Universidad de Los Andes y Pontificia Universidad Javeriana, 2016.

$\mathrm{Al}$ empezar a estudiar en una facultad de derecho latinoamericana, lo primero que se aprende es el origen europeo de nuestros ordenamientos. En general, no es extraño tener bien grabados en nuestra memoria jurídica algunos hechos y figuras como las anfictionas, las capitulaciones de Santa Fe, la Paz de Westfalia, las revoluciones industriales o las guerras mundiales. Sucesos e hitos del Viejo Mundo que al parecer marcaron el curso de la historia y del derecho internacional. Pero, ¿qué ocurre con nuestras historias y nuestros testigos?

La obra Imperialismo y derecho internacional pone de presente este interrogante y da luces sobre su respuesta. Este libro recoge varios ensayos que buscan presentar otra cara del derecho internacional. Es así como, a partir de las perspectivas críticas, el libro cuestiona la construcción, el andamiaje y, en general, el funcionamiento mismo de lo que conocemos hoy por derecho internacional.

Los compiladores de la obra hacen un gran trabajo al seleccionar algunas de las contribuciones más significativas del debate sobre la relación entre imperialismo y derecho internacional, escritas por tres de los mayores exponentes de algunas escuelas críticas.

En primer lugar, Antony Anghie, con "La evolución del derecho internacional: realidades coloniales y poscoloniales", identifica algunas de aquellas

Coordinador editorial de la Revista Derecho del Estado. Asistente de investigación, Departamento de Derecho Constitucional, Universidad Externado de Colombia. Contacto: daniel. rivas@uexternado.edu.co

Para citar el artículo: Rivas RAMÍREZ, D. Del colonialismo a la emancipación epistémica. Un aporte doble al debate sobre la relación entre imperialismo y derecho internacional. Derecho del Estado n. ${ }^{\circ}$ 39, Universidad Externado de Colombia, julio-diciembre de 2017, pp. 17-19. DOI: https://doi.org/10.18601/01229893.n39.01 https://doi.org/10.18601/01229893.n39.02 
estructuras que tuvieron su origen en el colonialismo y, en consecuencia, las formas en las que han limitado la comprensión de las relaciones entre el derecho internacional y el imperialismo.

Por su parte y en segundo lugar, Martti Koskenniemi señala, en "Imperio y derecho internacional: la verdadera contribución española", los aportes de los juristas clásicos españoles. Desde una aproximación diferente a los estudios poscoloniales tradicionales, el autor sostiene que el estudio exclusivo de las actividades públicas soberanas y el imperialismo formal conduce a un entendimiento sesgado y parcial del derecho internacional.

Finalmente, en “¿El pasado como derecho o como historia? La relevancia del imperialismo para el derecho internacional moderno", Anne Orford distingue entre las nociones de historia y de pasado; reivindica la importancia de este último en la compresión del derecho internacional, y desde allí apunta la necesidad de comprenderlo como una disciplina en perpetua transformación.

Sin embargo, resulta aún más valioso -en particular para la academia local- el "Estudio preliminar" de la publicación. Este texto, escrito a tres manos por Luis Eslava, Liliana Obregón y René Urueña, funge como un instrumento de navegación que le ofrece al lector de la obra un contexto y unas nociones básicas, medulares, necesarias y transversales para la compresión de los demás capítulos.

Además, este ensayo introductorio, "Imperialismo(s) y derecho(s) internacional(es): ayer y hoy", constituye una contribución sustancial a los acercamientos crítico-poscoloniales al derecho internacional a partir de tres grandes aportes. En efecto: 1) en primer lugar, los autores dan muestras de las nociones e instituciones actuales -acunadas por el ordenamiento internacional-que tienen marcados sesgos imperialistas ${ }^{1} ; 2$ ) por otra parte, exploran y develan una serie de hitos -diferentes a los europeos-que permiten contar otras historias -del derecho internacional- ${ }^{2} ; \mathrm{y}, 3$ ) finalmente, reconocen que a pesar de existir algunas iniciativas latinoamericanas en materia de derecho internacional, estas se ven viciadas desde su origen ${ }^{3}$.

Ahora bien, el interesante contenido que presentan estos tres autores en la sección inicial del libro no es el único mérito que se les puede atribuir. A decir verdad, además de su contribución al debate, el libro en general tiene una serie de virtudes que lo hacen especial dentro de lo excepcional.

Para empezar, se trata de un resquicio al tradicional elitismo que ha caracterizado la disciplina del derecho internacional en Colombia y en América

1 Es el caso de la noción de territorios, el principio de autodeterminación, el fenómeno de la descolonización, el FMI y los sistemas financieros, entre otros.

2 Son ejemplos de ello la aparición de la sustitución de las importaciones, la constitución de determinadas organizaciones internacionales, la aparición de la OMC, la teoría del desarrollo y la guerra contra el terrorismo.

3 Al respecto vemos que utilizan como ejemplos el derecho internacional latinoamericano, la aparición de la noción de América Latina y el mismo regionalismo, inter alia. 
Latina. Por lo general, en el continente, el aprendizaje del derecho internacional, y en especial de los estudios críticos, se hace especialmente difícil por el problema que supone la brecha del lenguaje y la reducida bibliografía en castellano. Aún más cuando se trata del acceso a nuevas y diferentes teorías con respecto a la perspectiva ortodoxa-normativista que suele imperar en la región.

Es gracias a este tipo de aportes que podría pensarse en oxigenar la educación en derecho internacional dentro de nuestras escuelas de derecho. Solo a partir de ellos será posible formar abogados y juristas internacionalistas con capacidad crítica y de discernimiento que les permita ver la panorámica y no un simple encuadre ${ }^{4}$. En otras palabras, solo al abrirnos a estas nuevas escuelas podremos formar(nos) con versatilidad y corrección.

Por otra parte, es de aplaudir el hecho de que se trate de una obra híbrida que mezcla voces del Norte y del Sur global. En particular, cabe resaltar que las voces latinoamericanas críticas empiezan por fin a publicar en su lengua materna, pensando en términos de América Latina y para América Latina ${ }^{5}$. Incluso me atrevería a afirmar que con Imperialismo y derecho internacional se hace un primer intento por realizar una inversión del sistema, en donde la periferia pasa al centro y el centro, a la periferia.

En conclusión, se trata de una obra que invita e incita a la academia de la región a renovarse. Motiva y promueve a sus lectores a estudiar otras historias del derecho internacional y brinda herramientas que no solo cuestionan el colonialismo (o imperialismo) en el derecho internacional, sino que también acaban con el colonialismo epistémico que caracteriza a esta disciplina.

Daniel Rivas Ramírez

Joven Investigador

Universidad Externado de Colombia

4 Al respecto vemos cómo Pablo Martín habla de una visión interparadagmática, Andrea Bianchi habla de un caleidoscopio, Paola Andrea acosta de una consciencia metodológica o paradigmática, y Luis Eslava de la necesidad de superar un único juego de lentes. Ver MARTíN RoDRíguez, P. Los paradigmas del derecho internacional: ensayo interparadigmático sobre la comprensión científica del derecho internacional. Granada: Universidad de Granada, 2008; BIANCHI, A. International Law Theories: An inquiry into different ways of thinking. Oxford: Oxford University Press, 2016; Acosta Alvarado, P. A. Enseñar e investigar derecho internacional en Latinoamérica: un ejercicio de catarsis. Serie Documentos de Trabajo n. ${ }^{\circ}$ 46, Departamento de Derecho Constitucional, Universidad Externado de Colombia; Eslava, L. Istanbul vignettes: Observing the everyday operation of International Law. London Review of International Law, 2014, 2(1) 3-47.

5 Es de anotar que aun cuando existe un buen grupo de académicos latinoamericanos que trabajan desde perspectivas críticas, la regla general es que lo hagan fuera de la región y publiquen en inglés. 